A MEASURE of Francis Bacon's influence and importance to the history of ideas lies in the number of ways in which his works can be studied, and the number of books written about him. Not so long ago it was the fashion to emphasise his modernity and see in his writings the nascent scientific revolution of the 17th century. Now there is a useful corrective in a tendency to regard him as a Renaissance man (he was three years older than Shakespeare and Galileo) and to examine his thought in terms of 16th century concepts.

Out of this latter tendency comes Dr Jardine's extremely learned and lively study, based upon a scholarly examination of the dialectical tradition to which Bacon was exposed at Cambridge and which, as Dr Jardine shows, he never entirely shook off. There were in the later 16th century many new treatises on the art of discourse, intended to teach the young student both the art of logical argument and its application in rhetoric. Here we see how Bacon duly followed their precepts in all his works to some extent, most especially in his literary writings and in his logic; it is useful to be reminded what is easy to overlook, that the Novum Organum is first and foremost a logical or dialectical work, and only secondarily scientific.

This said, it must be added that this is not the whole of Bacon; this Bacon is studious, scholarly, derivative, pedantic, and eminently forgettable. There is another Bacon, who transcended his

\section{Sides of Bacon}

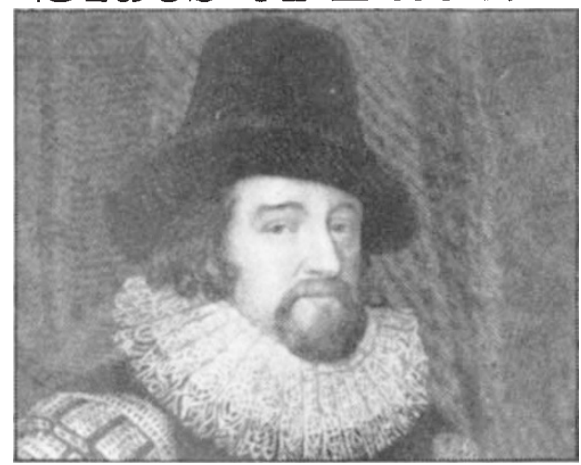

Francis Bacon: Discovery and the Art of Discourse. By Lisa Jardine. Pp. viii + 267. (Cambridge University Press : London, 1974.) £4.90; \$15.50.

sources and his dialectical methods of thought to fire the imagination of budding natural philosophers born after (sometimes long after) he wrote. It is revealing to consider Bacon's elaboration of forms in terms of his dialectical education, but it provides neither the whole meaning nor any of the relevance of his work to the advancement of science. Dr Jardine is eminently successful in showing the traditional content; her approach cannot and does not help us to understand why it was important to later natural philosophers that Bacon said of heat that it was "a motion, expansive, restrained, and acting in its strife on the smaller parts of bodies". Nor does it allow us to appreciate that it was relevant to the development of the mechanical philo- sophy that Bacon connected the "form of whiteness" with the reflectivity of the small particles of bodies. The scientist and historian of science looks favourably upon Bacon's remark: "A leaden ball of a pound weight dropped from a tower reaches the ground in (say) ten seconds: will a ball of two pounds in weight (in which the force of natural motion, as they call it, ought to be doubled) reach the ground in five seconds? No, but it will take almost the same time in falling, and will not be accelerated in proportion to the increase of quantity". Surely this is close to the heart of advancing science in 1623 .

It may be true, as Dr Jardine says, that "in treating systematic experimenting as subsidiary to a formal logic which manipulates essential definitions

Bacon dismissed as secondary and provisional much of what we now regard as science"; but did he dismiss so much of what was then called natural philosophy? Rather, may it not be the case that his casting of new ideas in an old framework and his use of the language and methods of thought in which his readers in the next two generations were as thoroughly trained as he had been, made these ideas easier to understand, and certainly no less effective?

But modern readers, not so educated, are less able to appreciate the 16th century context of Bacon's thought and, above all, expression. Dr Jardine's book is valuable in providing understanding.

Marie Boas Hall The book achieves these aims effec-
tively, especially the first; the second category of readers may find some (not all) of the chapters somewhat elementary for their requirements. The book is in line with that trend. This description is in no way to be construed as an implicit criticism, for there has been a clear need for just such a volume. According to the preface, "the principal aim of the book is to provide a balanced and integrated account of instrumental methods (used for the characterisation of materials) for those who carry responsibility for research programmes and who must be able to judge the potential contribution from alternative techniques, and for specialists in any one technique who require an overview in adjacent fields of work". diffraction, 7 with micrographic methods (with a heavy emphasis on electron instruments), 7 on diverse methods of chemical analysis by physical means (optical emission and absorption spectrometry; electron-probe microanalysis; Auger, X-ray and mass spectrometry; activation analysis) and 2 with Mössbauer and magnetic resonance spectroscopy, regarded primarily as means of chemical identification.

Loosely, the book offers advice on how to find out what it looks like and what it's made of. The advances of the last 15 years have changed these twin arts out of all recognition, and this book offers a useful outline of what is now feasible. Some of the techniques are still difficult enough to oblige the wise casual user to contract the work out: Harwell is ready and waiting.

R. W. Cahn 